\section{IJ\$ER}

ISSN: 2149-5939

\title{
Sekizinci sınıf öğrencilerinin doğal sayı, ondalıklı sayı, kesirler ve yüzde konularında kullandıkları sayı duyusu stratejilerin incelenmesi ${ }^{1}$
}

\author{
Investigation of number sense strategies used by eight grade on the subject of natu- \\ ral numbers, decimal numbers, fractions, percentages of eight grade students
}

Zübeyde Er²

Received Date: 01 / 09 / 2016
Perihan Dinç Artut ${ }^{3}$

Accepted Date: $23 / 12$ / 2016

$\ddot{O} z$

Bu çalışma da sekizinci sınıf öğrencilerinin doğal sayılar, ondalıklı sayılar, kesirler ve yüzdeler konularını içeren sayı duyusu problemlerinde kullandıkları stratejilerin belirlenmesi amaçlanmıştır. Tarama modelinde betimsel bir çalışma olan bu araştırmada, verileri toplamak amacıyla nitel ve nicel veri toplama teknikleri birlikte kullanılmıştır. Araştırmanın nicel örneklemi Adana ilindeki devlet okullarında öğrenim gören sekizinci sınıfa devam eden 200 ögrenciden oluşmaktadır. Araştırmanın nitel boyutu ise kolay ulaşılabilir durum örneklemesine göre seçilen 3 farklı ortaokula devam eden, gönüllülük esasına dayalı olarak belirlenen 40 ögrenci üzerinde yürütülmüştür. Veri toplama aracı olarak sayı duyusu testi kullanılmıştır. Veri toplama aracından elde edilen veriler nicel ve nitel analiz yöntemleriyle analiz edilmiştir. Nicel ve nitel verilerin analizinden elde edilen bulgulara göre öğrencilerin sayı duyusu performanslarının düşük olduğu ve ögrencilerin çözümlerin de daha çok kural temelli stratejileri kullandiklarl görülmüştür.

Anahtar Sözcükler: Doğal sayılar, kesirler, ondalıklı sayılar, sayı duyusu stratejileri, yüzdeler

\begin{abstract}
In this research, the aim is to determine the strategies which the $8^{\text {th }}$ grade students use in number sense problems involving on the subject of natural numbers, decimal numbers, fractions, percentages. In this research, a descriptive study was designed as a cross hatching model. There were two techniques used for data collection; which were quantitative and qualitative methods. The quantitative participants of the research consisted of 200 students who were attending at the $8^{\text {th }}$ grade of three middle schools in Adana. The qualitative participants of the research consisted of 40 students who attending 3 different middle schools and identifying according to voluntary basis. Number sense test was used as the data collection tool. The data obtained through the data collection tool were analysed via quantitative and qualitative analysis technics. According to the findings obtained from the analysis of quantitative and qualitative data, it was seen that the students had low number sense performances and that the solutions of the students also used more rule based strategies.
\end{abstract}

Keywords: Number sense strategies, natural numbers decimal numbers, fractions, percentages.

\section{Giriş}

Sayı duyusu, kavramına ilişkin çeşitli tanımlar, literatürde yapılmıştır. Greeno (1991) sayı duyusunu, esnek düşünme, hesaplamada tahmin becerisi ve sayısal miktarlar hakkındaki muhakeme yeteneği olarak tanımlamıştır. Sayı duyusu bazı araştırmalarda (Courtney- Clerk 2012; Reys ve Yang, 1998; Tsao, 2011) kişinin sayılar ve sayıların işlemler üzerindeki genel anlayışı, bu anlayışı esnek bir şekilde kullanarak matematiksel yorumlar yapabilme; sayılar ve işlemlerle ilgili faydalı

\footnotetext{
${ }^{1}$ Bu çalışma SBA-2016-5641 kodlu proje kapsamında Çukurova Üniversitesi BAP biriminden destek alınmıştır. ${ }^{2}$ Çukurova Üniversitesi, Adana, Türkiye, zbeyde-er@ windowslive.com

${ }^{3}$ Çukurova Üniversitesi, Adana, Türkiye, partut@cu.edu.tr
} 
Er, Z., Dinç Artut, P. (2017). Investigation of number sense strategies used by eight grade on the subject of natural numbers, decimal numbers, fractions, percentages of eight grade students. International Journal of Social Sciences and Education Research, 3(1), 218-229.

ve etkili stratejiler geliştirebilme yeteneği ve eğilimi olarak ifade edilmektedir. En genel tanımı ile Hope'a (1989) göre ; sayı duyusu, sayıların çeşitli kullanım alanları hakkında mantıklı tahminler yapabilme, aritmetik hataları fark edebilme, en etkili hesaplama yolunu seçebilme ve sayı örüntülerini fark edebilme hissidir.

Sayı duyusu kavramı, matematik eğitiminde önemli bir kavramdır. NCTM (2000, s32) standartlarına göre okul öncesi dönemden orta öğretim döneminin sonuna kadar öğrenim gören öğrenciler sayıları, sayıları temsil yollarını, sayılar arasındaki ilişkileri ve sayı sistemlerini anladığı, işlemlerin anlamını ve birbirleriyle ilişkili olduklarını anladığı, akıcı bir şekilde hesaplama ve uygun tahminler yapabildiği belirtilmiş ve bu standartların temelinde ise sayı duyusu kavramının gelişmiş olması gerektiğini vurgulanmıştır. Kısacası, sayı duyusuna sahip bir birey, okul ve günlük hayat matematiğini esnek ve kendi işini kolaylaştıracak bir şekilde kullanabilir.

TIMSS ve PISA gibi uluslararası sınavlarda; öğrencilerden matematik ile ilgili soruları doğru yorumlamaları, sağlıklı bir şekilde tahminde bulunmaları ve akıl yürütebilmeleri beklenmektedir. Öğrencilerde sayı duyusunun gelişmesi ile akıl yürütme, tahmin etme, ilişkilendirme, zihinden hesaplama, yargıda bulunma gibi beceriler gelişmektedir (Harç, 2010). Ancak her iki sınava ilişkin sonuçlar, Türk öğrencilerinin başarı sıralamasında beklenen düzeyde olmadığını göstermektedir. Bu bağlamda sayı duyusunun gelişiminin önemli olduğu düşünülmektedir.

Ortaokul matematik dersi öğretim programında sayılar ve işlemler, cebir, geometri ve ölçme, veri işleme ve olasılık olmak üzere beş öğrenme alanı bulunmaktadır. Bazı sınıf seviyelerinde bu öğrenme alanlarından tümü yer alırken, bazılarında hepsine yer verilmemiştir. Olasılık öğrenme alanı sadece sekizinci sınıfta yer alırken, cebir öğrenme alanı beşinci sınıf dışındaki tüm sınıflarda yer almaktadır. Sayılar ve işlemler, geometri ve ölçme ve veri İşleme öğrenme alanlarına tüm sınıf düzeylerinde yer verilmiştir (MEB, 2013).

Ortaokul matematik programı incelendiğinde sayı duyusunun kavram olarak programda yer almadığı görülmektedir. Bununla birlikte sayı duyusu ile ilgili zihinden işlem yapma, tahmin etme gibi beceriler programda yer almaktadır. Programda sayılar ve işlemler öğrenme alanına ilişkin zihinden işlem yapma ve tahmin etme becerileri ile ilgili beşinci sınıfta dört kazanım(Doğal sayılarla toplama ve çıkarma işlemlerinin sonuçlarını tahmin eder, Doğal sayılarla çarpma ve bölme işlemlerinin sonuçlarını tahmin eder, Iki basamakl doğal saylarla zihinden toplama ve çıkarma işlemlerinde uygun stratejiyi seçerek kullanır, Doğal sayllarla zihinden çarpma ve bölme işlemlerinde uygun stratejiyi seçerek kullanır) ve altıncı sınıfta iki kazanım (Kesirlerle yapılan işlemlerin sonucunu tahmin eder, Sayıların ondalık gösterimleriyle yapılan işlemlerin sonucunu tahmin eder) olduğu görülmektedir. Bunun yanı sıra yedinci sınıfta bir kazanım (Bir çokluğun belirtilen bir yüzdesine karşılık gelen miktarı bulur; belirli bir yüzdesi verilen çokluğu bulur) ve ve sekizinci sınıfta bir kazanım (Tam kare olmayan sayıların karekök değerlerinin hangi iki doğal sayı arasında olduğunu belirler) olmak üzere iki kazanım bulunmaktadır. Bu bağlamda, bu öğrenme alanı ile ilgili tüm sınıf düzeyleri birlikte düşünüldüğünde toplam sekiz kazanımın olduğu görülmüş̧ür.

Sayı duyusu konusu ile ilgili yapılan çalışmalarda genel olarak, tasarlanan eğitimlerin uygulanması ile sayı duygusunun geliştirilmesi, öğrencilerin sayı duygusu seviyeleri, sayı duygusunun ile tahmin, hesaplama becerileri ile ilişkileri üzerinde durulmuştur (Harç,2010). Ayrıca sayı duyusu bileşenleri açısından sayı duyusu düzeylerinin belirlendiği çalışmalara da rastlanmıştır. Ulaşılabilen kaynaklar incelendiğinde ilgili literatürde kesirler konusunda öğrencilerin sayı duyusu 
Er, Z., Dinç Artut, P. (2017). Sekizinci sınıf öğrencilerinin doğal sayı, ondalıklı sayı, kesirler ve yüzde konularında kullandıkları sayı duyusu stratejilerin incelenmesi. International Journal of Social Sciences and Education Research, 3(1), 218-229.

gelişimlerinin belirlendiği (Reys, Kim ve Bay, 1999; Yang ,2002), kesirlerde ve ondalık sayılarda sayı duyusu kullanımına ilişkin (Suh, Johnston, Jamieson ve Mills 2008), sayı duyusunun yüzde konusundaki kullanımı (Gay ve Aichele ,1997) ile ilgili sayı duyularına belirlemeye yönelik çalışmalar yapıldığı görülmüştür. Sayılar, kesirler, ondalıklı sayılar ve yüzdeler konularına yönelik öğrencilerin sayı duyularını belirlemesi ve bu konulara yönelik problemleri çözerken kullanılan sayı duyusu stratejilerinin belirlenmesinin birlikte ele alındığı bir çalışmaya rastlanmamıştır.

Yukarıda yapılan açıklamalar doğrultusunda bu çalışmanın genel amacı sekizinci öğrencilerinin sayı duyusu performanslarının ve sayı duyusu problemlerinde kullandıkları stratejilerin incelenmesidir. $\mathrm{Bu}$ amaç doğrutusunda araştırmanın alt amaçları aşağıda verilmiştir.

- Sekizinci sınıf öğrencilerinin sayı duyusu performanslarının nedir?

- Sekizinci sınıf öğrencilerinin doğal sayılara ilişkin kullandıkları sayı duyusu stratejileri nelerdir?

- Sekizinci sınıf öğrencilerinin kesirler konusuna ilişkin kullandıkları sayı duyusu stratejileri nelerdir?

- Sekizinci sınıf öğrencilerinin ondalıklı sayılara ilişkin kullandıkları sayı duyusu stratejileri nelerdir?

- Sekizinci sınıf öğrencilerinin yüzde konusuna ilişkin kullandıkları sayı duyusu stratejileri nelerdir?

\section{Yöntem}

$\mathrm{Bu}$ araştırma, sekizinci sınıf öğrencilerinin doğal sayılar, ondalıklı sayılar, kesirler ve yüzdeler konularını içeren sayı duyusu problemlerinde kullandıkları stratejilerin belirlenmesini amaçlayan nicel ve nitel araştırma yöntemlerin birlikte kullanıldığı tarama modelinde betimsel bir çalışmadır.

Araştırmanın nicel örneklemi, küme örnekleme yöntemi ile belirlenen Adana ilindeki 3 farklı devlet okulunun sekizinci sınıflarına devam eden 200 (114 kız, 86 erkek) öğrenciden oluşmaktadır. Araştırmanın nitel boyutu ise kolay ulaşılabilir durum örneklemesine göre seçilen 3 farklı ortaokula devam eden, gönüllülük esasına dayalı olarak belirlenen 40 (28 kı 12, erkek) öğrenci üzerinde yürütülmüştür.

\subsection{Veri toplama aract}

Veri toplama aracı öğrencilerin doğal sayılar, ondalıklı sayılar, kesirler ve yüzde konularını içeren sayı duyusu problemlerini çözerken kullandıkları stratejiyi belirlemeye yönelik Singh, (2009)'in McIntosh, Reys, Reys Bana, ve Farrell, (1997)' dan uyarlamış olduğu sayı duyusu ölçeğindeki bazı sorulardan oluşturulmuştur. Test, doğal sayılar (Madde no:13, 21, 22, 25), ondalık sayılar (Madde no:1, 6, 10, 11, 14, 15, 16, 17,20,23 ), kesirler(Madde no:2, 3, 4, 5, 7, 8, 9, ) ve yüzdeler (Madde no:12,18, 19,24, 26 ) konularını içeren 26 maddeden oluşmaktadır.

\subsection{Verilerin toplanması}

Araştırmanın nicel verilerini elde etmek için Sayı Duyusu Testi (SDT) her bir öğrenciye bireysel olarak uygulanmıştır. Uygulama sürecinde öğrencilerin sayı duyularını belirlemek amacyyla öğrencilere her bir maddeye yaklaşık 30-45 saniye zaman ayırmaları gerektiği ve sayı duyusu testindeki maddelere ilk akıllarına gelen çözümleri yapmalarının beklendiği söylenmiştir.

Nitel veriler, doküman analizi ve görüşme tekniği kullanılarak elde edilmiştir. Doküman olarak 40 öğrencinin sayı duyusu testine verdikleri cevaplar kullanılmıştır. Görüşmeler, aynı öğrencilere sayı duyusu testinde yer alan doğal sayılar, ondalıklı sayılar, kesirler ve yüzdeler konularını 
Er, Z., Dinç Artut, P. (2017). Investigation of number sense strategies used by eight grade on the subject of natural numbers, decimal numbers, fractions, percentages of eight grade students. International Journal of Social Sciences and Education Research, 3(1), 218-229.

içeren soruları çözerken kullandıkları stratejiyi belirlemek amacıyla yapılmıştır. Görüşmeler sırasında öğrencilere her bir soruya ilişkin vermiş oldukları cevaplar tekrar gösterilmiş ve bu cevaba nasıl ulaştıkları sorulmuş ve nasıl düşündüklerini açıklamaları istenmiştir. Görüşmeler kayıt cihazı aracılığıyla kaydedilmiştir

\subsection{Verilerin analizi}

Araştırma kapsamında elde edilen nicel veriler, bilgisayar ortamında analiz edilmeden önce sayı duyusu testinde tüm maddelerin yönergeye göre cevaplanıp cevaplanmadığına bakılmış, eksik bırakılan madde olup olmadığı kontrol edilmiştir.

Verilerin analizi, bilgisayar ortamında SPSS 15.0 programında yapılmış, araştırmanın amacı doğrultusunda uygulamaya katılanların, sayı duyusu becerilerine ilişkin frekans (f), yüzde (\%) ve aritmetik ortalama (X ) değerleri hesaplanmıştır. Doğru cevap verilen maddeler "1", yanlış cevap verilen maddeler ise " 0 " puan verilerek değerlendirilmiştir. SDT nin alfa güvenirlik 0.78 olarak hesaplanmıştır.

Ses kayıtlarının yazıya aktarılmasıyla elde edilen nitel veriler ise betimsel analiz teknikleri kullanılarak analiz edilmiştir. Betimsel analiz, verilerin daha önceden belirlenen temalara göre özetlenip yorumlanmasıdır (Yıldırım ve Şimşek, 2006).

Görüşme yapılan öğrencilerin kimliklerini açıklamamak için Ö1, Ö2, Ö3 .....biçiminde kodlar verilmiştir. Sayı duyusu problemlerinin çözümünde kullanılan stratejiler, ilgili literatür bulguları da incelenerek, Say1 duyusu temelli strateji (SDTS), kısmen dayı duyusu temelli strateji (KSDTS), kural temelli strateji (KTS) ve herhangi bir açıklama yapılmayan cevaplar (Açılamasız) olmak üzere dört kategori olarak kodlanmıştır. Bu kategorilerin içeriği aşağıda verilmiştir.

Sayı duyusu temelli strateji (SDTS): Sayıların anlamını bilme, sayıların göreceli büyüklüğünü bilme, referans noktası kullanma, sayıların işlemler üzerindeki etkilerini bilme, sonucu tahmin etme ve uygunluğunu değerlendirebilmeyi içerir(Şengül, 2013).

Kısmen dayı duyusu temelli strateji (KSDTS): Sayı duyusu temelli ve kural temelli stratejilerin birlikte kullanıldı durumları içerir.

Kural temelli strateji (KTS): Problemin çözümünü yaparken belli kurallara bağlı kalarak veya işleme dayalı olarak sonuç bulmayı içerir.

Herhangi bir açılama yapılmayan cevap (Açıklamasız): Cevap verilmeyen veya açılama yapılmayan cevapları içermektedir.

\section{Bulgular}

\section{Öğrencilerinin sayı duyusu performanslarına ilişskin genel bulgular ve yorum}

Tablo 1 de sayı duyusu problemlerine verilen cevaplarda öğrencilerin cinsiyete göre aritmetik ortalamaları verilmiştir.

Tablo 1. Cinsiyete göre sayı duyusu performansları

\begin{tabular}{lll}
\hline Cinsiyet & $\mathrm{N}$ & A.O \\
\hline Kiz & 114 & 11.18 \\
Erkek & 86 & 11.01 \\
\hline TOPLAM & 200 & 11,11 \\
\hline
\end{tabular}


Er, Z., Dinç Artut, P. (2017). Sekizinci sınıf öğrencilerinin doğal sayı, ondalıklı sayı, kesirler ve yüzde konularında kullandıkları sayı duyusu stratejilerin incelenmesi. International Journal of Social Sciences and Education Research, 3(1), 218-229.

Tablo 1 incelendiğinde SDT de bulunan 26 maddeye verilen cevaplardan tüm öğrencilerin aritmetik ortalamalarının 11.11 olduğu görülmektedir. Sayı duyusu testindeki madde sayısının 26 olduğu göz önüne alındığında öğrencilerin sayı duyularının düşük olduğu söylenebilir.

Öğrencilerin Sayı Duyusu Problemlerindeki Doğal Sayılar Konusuna Yönelik Kullandıkları Stratejilere İlişkin Bulgular Ve Yorumlar

Tablo 2'de bu doğal sayılar konusuna yönelik maddelere öğrencilerin cevaplarında (40x4=160) kullandıkları stratejilere ilişkin frekans ve yüzde dağılımı verilmiştir.

Tablo 2. Doğal sayılar ile ilgili maddelerde kullanılan stratejilere ilişkin dağılım

\begin{tabular}{lll}
\hline & F & $\%$ \\
\hline SDTS & 17 & 10.62 \\
KSDTS & 3 & 1.87 \\
KTS & 122 & 76.25 \\
AÇIKLMASIZ & 18 & 11.25 \\
\hline TOPLAM & 160 & 100 \\
\hline
\end{tabular}

Tablo 2 incelendiğinde SDT 'deki doğal sayılar konusu ile ilgili maddelere verilen yanıtlardaki kullanılan stratejilere ilişkin öğrencilerden elde edilen cevapların \%10.62 si sayı duyusu temelli, \%1.87'sı kısmen sayı duyusu temelli, \%76.25 'u kural temelli stratejileri kullandıkları görülmektedir. Bunun yanı sıra öğrencilerle yapılan görüşmelere ilişkin bazı örnekler aşağıda (Şekil 1 ve Şekil 2 ) verilmiştir.

Şekil 1. Kural temelli strateji ile çözüm

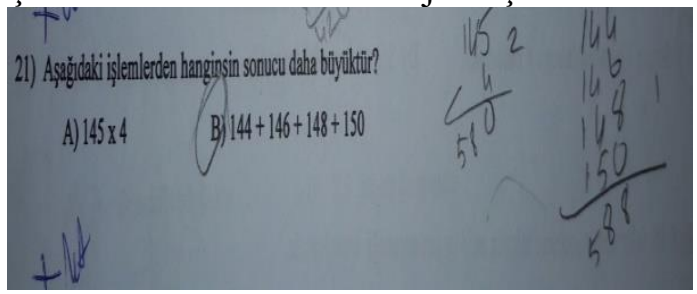

Şekil 2. Sayı duyusu temelli strateji ile çözüm

SDT 'deki 21. Madde için Şekil 1deki cevabı veren öğrencinin bu cevabına ilişkin açıklaması

" 145 ile 5 'i çarptım ve sonucu 580 olarak buldum. Daha sonra B seçeneğindeki tüm sayıları alt alta topladım ve sonucu 588 olarak buldum. Dolaylstyla B seçeneği daha büyük olur(Ö39)" biçimindedir. Şekil 1' deki çözüm ve öğrencinin bu konudaki görüşleri birlikte değerlendirildiğinde Ö29 çözümünde kural temelli stratejiyi kullandığı biçiminde yorumlanabilir.

Şekil 2'deki cevabı veren öğrencinin bu cevabına ilişkin açıklaması

"A seçeneğinde 4 tane 145 var, B seçeneğinde 1 tane 145 'ten küçük bir sayl var ve diğer 3 sayı 145 'ten büyük, dolaylsıyla B seçeneğinin değeri daha büyüktür diye düşündüm(Ö40) " biçimindedir. Şekil 2' deki çözüm ve öğrencinin bu konudaki görüşleri birlikte değerlendirildiğinde onun çözümünde sayı duyusu temelli stratejiyi kullandığı biçiminde yorumlanabilir.

Öğrencilerin Sayı Duyusu Problemlerindeki Ondalıklı Sayılar Konusuna Yönelik Kullandıkları Stratejilere İlişkin Bulgular Ve Yorumlar

Tablo 3'de ondalıklı sayılar konusuna yönelik maddelere öğrencilerin cevaplarında $(40 \times 10=400)$ kullandıkları stratejilere ilişkin frekans ve yüzde dağılımı verilmiştir. 
Er, Z., Dinç Artut, P. (2017). Investigation of number sense strategies used by eight grade on the subject of natural numbers, decimal numbers, fractions, percentages of eight grade students. International Journal of Social Sciences and Education Research, 3(1), 218-229.

Tablo 3. Ondalıklı sayılar ile ilgili maddelerde kullanılan stratejilere ilişkin dağılım

\begin{tabular}{lll}
\hline & F & $\%$ \\
\hline SDTS & 73 & 18.25 \\
KSDTS & 5 & 1.25 \\
KTS & 211 & 52.75 \\
AÇIKLMASIZ & 111 & 27.75 \\
\hline TOPLAM & 400 & 100 \\
\hline
\end{tabular}

Tablo 3 incelendiğinde SDT 'deki ondalıklı sayılar ile ilgili maddelere verilen yanıtlardaki kullanılan stratejilere ilişkin öğrencilerden elde edilen cevapların \%18.25'i sayı duyusu temelli, $\% 1.25$ 'i kısmen sayı duyusu temelli, \%52.75 'i kural temelli stratejileri kullandıkları görülmektedir. Bunun yanı sıra öğrencilerle yapılan görüşmelere ilişkin bazı örnekler aşağıda (Şekil 3) verilmiştir.

Şekil 3. Kural temelli strateji ile çözüm

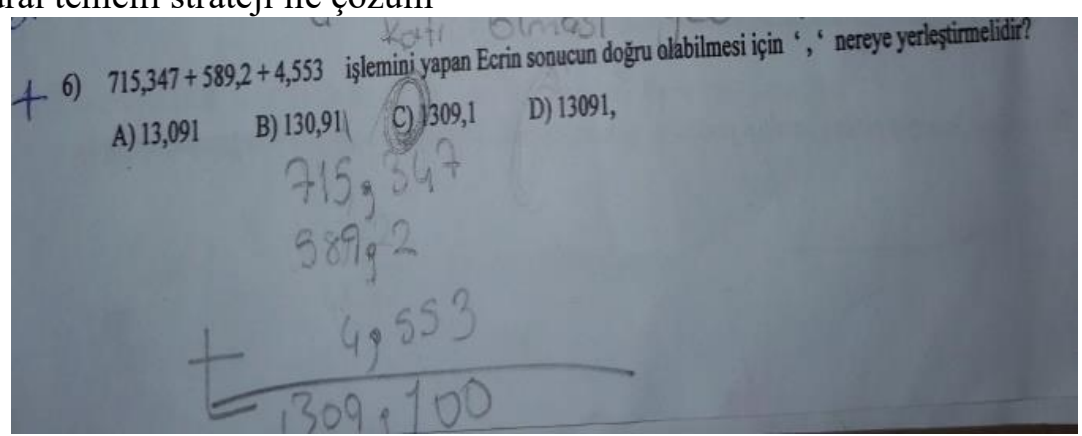

SDT ‘deki 6. Madde için Şekil 3deki cevabı veren öğrencinin bu cevabına ilişkin açıklaması

“Tüm sayıları alt alta topladım ve C seçeneği olduğunu buldum (Ö28)”

biçimindedir. Şekil 3' deki çözüm ve öğrencinin bu konudaki görüşleri birlikte değerlendirildiğinde Ö28 çözümünde kural temelli stratejiyi kullandığ biçiminde yorumlanabilir.

Ö26 'in bu maddeye ilişkin açıklaması

“ Ilk iki sayının tam kısmı 3 basamakll, 3. Sayının tam kısmı 1 basamaklı bir sayı. Dolayısıyla bu sayıları topladiğımda tam kısmı 4 basamaklı olan bir sayı elde etmem gerekir ve bu C seçeneğinde var(Ö26)".

biçimindedir. Öğrencinin bu konudaki görüşleri değerlendirildiğinde onun çözümünde say1 duyusu temelli stratejiyi kullandığı biçiminde yorumlanabilir.

Öğrencilerin Sayı Duyusu Problemlerindeki Kesirler Konusuna Yönelik Kullandıkları Stratejilere İlişkin Bulgular Ve Yorumlar

Tablo 4'de kesirler konusuna yönelik maddelere öğrencilerin cevaplarında $(40 \times 7=280)$ kullandıkları stratejilere ilişkin frekans ve yüzde dağılımı verilmiştir.

Tablo 4. Kesirler ile ilgili maddelerde kullanılan stratejilere ilişkin dağılım

\begin{tabular}{lll}
\hline & $\mathrm{F}$ & $\%$ \\
\hline SDTS & 19 & 6.78 \\
KSDTS & 10 & 3.57 \\
KTS & 159 & 56.78 \\
AÇIKLMASIZ & 92 & 32.85 \\
\hline TOPLAM & 280 & 100 \\
\hline
\end{tabular}


Er, Z., Dinç Artut, P. (2017). Sekizinci sınıf öğrencilerinin doğal sayı, ondalıklı sayı, kesirler ve yüzde konularında kullandıkları sayı duyusu stratejilerin incelenmesi. International Journal of Social Sciences and Education Research, 3(1), 218-229.

Tablo 4 incelendiğinde SDT 'deki kesirler ile ilgili maddelere verilen yanttlardaki kullanılan stratejilere ilişkin öğrencilerden elde edilen cevapların \%6.78‘si sayı duyusu temelli, \% 3,57’si kısmen sayı duyusu temelli, \%56.78 'si kural temelli stratejileri kullandıkları görülmektedir. Bunun yanı sıra öğrencilerle yapılan görüşmelere ilişkin bazı örnekler aşağıda (Şekil 4 ve Şekil 5) verilmiştir.

Şekil 4:Kural temelli strateji ile çözüm

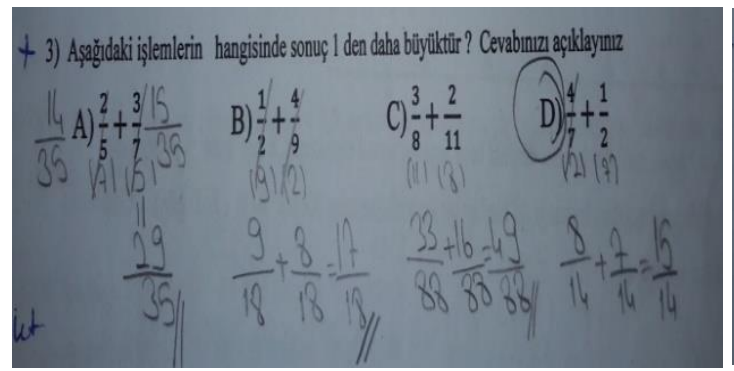

Şekil 5: Sayı duyusu temelli strateji strateji ile çözüm

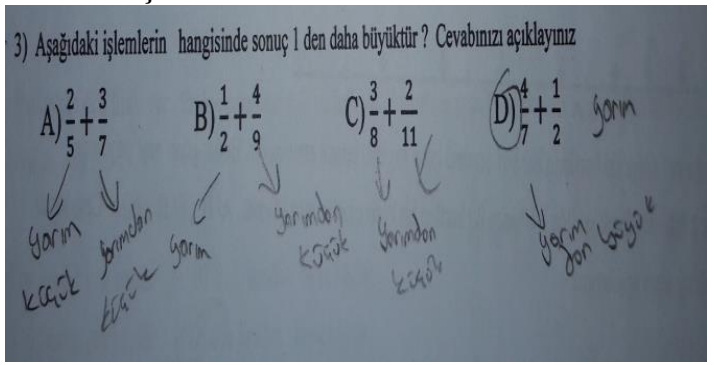

SDT ‘deki 3. Madde için Şekil 1deki cevabı veren öğrencinin bu cevabına ilişkin açıklaması

"Tüm seçeneklerde payda eşitleme yöntemini kullandığımda cevabı D seçeneği olarak buldumÖ9) ' biçimindedir. Şekil 4' deki çözüm ve öğrencinin bu konudaki görüşleri birlikte değerlendirildiğinde Ö9 çözümünde kural temelli stratejiyi kullandığ biçiminde yorumlanabilir.

Şekil 5'deki cevabı veren öğrencinin bu cevabına ilişkin açıklaması

"Yarımdan küçük, yarım veya yarımdan büyük olarak seçenekleri değerlendiğimde D seçeneği yarım ve yarımdan büyük bir sayının toplamı olduğu için cevap D seçeneğidir diye düşündüm (Ö33) ' biçimindedir. Şekil 5' deki çözüm ve öğrencinin bu konudaki görüşleri birlikte değerlendirildiğinde onun çözümünde sayı duyusu temelli stratejiyi kullandığı biçiminde yorumlanabilir.

Öğrencilerin Sayı Duyusu Problemlerindeki Yüzde Konusuna Yönelik Kullandıkları Stratejilere İlişkin Bulgular Ve Yorumlar

Tablo 5'de yüzdeler konusuna yönelik maddelere öğrencilerin cevaplarında (40x5=200) kullandıkları stratejilere ilişkin frekans ve yüzde dağılımı verilmiştir.

Tablo 5. Yüzdeler ile ilgili maddelerde kullanılan stratejilere ilişkin dağglım

\begin{tabular}{lll}
\hline & $\mathrm{F}$ & $\%$ \\
\hline SDTS & 73 & 36.50 \\
KSDTS & 3 & 1.50 \\
KTS & 100 & 50.00 \\
AÇIKLMASIZ & 24 & 12.00 \\
\hline TOPLAM & 200 & 100 \\
\hline
\end{tabular}

Tablo 5 incelendiğinde SDT 'deki yüzdeler ile ilgili maddelere verilen yanıtlardaki kullanılan stratejilere ilişkin öğrencilerden elde edilen cevapların \%36,50'si sayı duyusu temelli, \% 1.50 'si kısmen sayı duyusu temelli, \%50 'si kural temelli stratejileri kullandıkları görülmektedir. Bunun yanı sıra öğrencilerle yapılan görüşmelere ilişkin bazı örnekler aşağıda (Şekil 6 ve Şekil7) verilmiştir. 
Er, Z., Dinç Artut, P. (2017). Investigation of number sense strategies used by eight grade on the subject of natural numbers, decimal numbers, fractions, percentages of eight grade students. International Journal of Social Sciences and Education Research, 3(1), 218-229.

Şekil 6. Kural temelli strateji ile çözüm

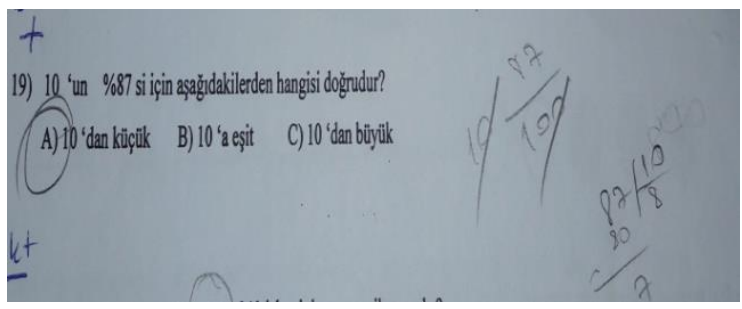

Şekil 7. Sayı duyusu temelli strateji strateji ile çözüm

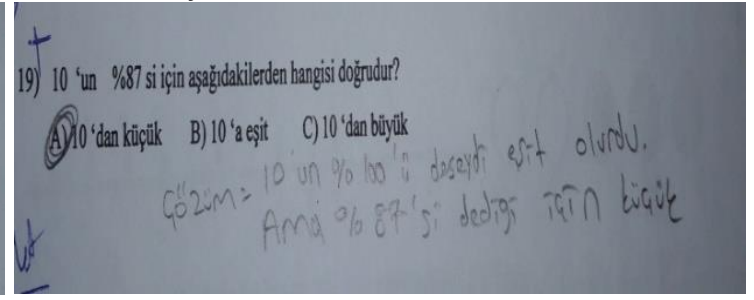

SDT ‘deki 19. Madde için Şekil 6 daki cevabı veren öğrencinin bu cevabına ilişkin açıklaması

“İşlemleri yaptım. 10' nun \%87 'sini 8 olarak buldum. Sonuç 10'dan küçük olur(Ö1)” biçimindedir. Şekil 6' daki çözüm ve öğrencinin bu konudaki görüşleri birlikte değerlendirildiğinde Ö1 çözümünde kural temelli stratejiyi kullandığı biçiminde yorumlanabilir.

Şekil 7'deki cevabı veren öğrencinin bu cevabına ilişkin açıklaması

“\%100 diye düşündüğümüzde 10 'a eşit olurdu. Dolaylstyla \%87 10’dan küçük olmal. (Ö25)“ biçimindedir. Şekil 7' deki çözüm ve öğrencinin bu konudaki görüşleri birlikte değerlendirildiğinde onun çözümünde sayı duyusu temelli stratejiyi kullandığg biçiminde yorumlanabilir.

\section{Tartışma, sonuç ve öneri}

Öğrencilerden elde edilen tüm çözümler incelendiğinde doğal sayılar, ondalıklı sayılar kesirler ve yüzdeler konularını içeren sayı duyusu problemlerine yönelik yapılan nicel analiz sonucunda, öğrencilerin sayı duyu performanslarının düşük olduğu ve cinsiyete göre sayı duyusu performansları arasında anlamlı farklılık olmadığı sonucuna ulaşılmıştır.

Altay (2010) tarafından yapılan çalışmada ilköğretim ikinci kademe öğrencilerinin sayı duyularının oldukça düşük olduğu ortaya koyulmuştur. Bunun yanı sıra Harç (2010) altıncı sınıf öğrencilerinin sayı duyusu bileşenlerine profillerinin belirlenmesine yönelik çalışmasında çok az sayıda öğrencinin soruları sayı duyusunu kullanarak cevapladığı ve büyük bir çoğunluğunun işlem ve kurallı temelli çözümleri kullandığını ifade etmektedir. Bu bağlamda bu araştırmanın sonucu ile Altay (2010) ve Harç (2010) sonuçlarının benzer olduğu söylenebilir.

Reys, Reys, Emanuelsson, Johansson, McIntosh ve Yang (1999) tarafından yapılan çalışmada Amerikalı, Tayvanlı, Avustralyalı ve İsveçli öğrencilerin sayı duyusu problemlerine ilişkin başarılarının düşük olduğu ortaya koyulmuştur. Onlar bu düşük başarıyı, okullarda uygulanan matematik programının işleme dayalı hesaplamalara ağırlık vermesine bağlamışlardır. Bu doğrultuda bu çalışmada da öğrencilerin sayı duyusu performanslarının düşük olmasının bir nedeni ülkemiz ortaokul matematik programında sayı duyusu kazanımlarına yeterince yer verilmemiş olması olabilir.

Öğrencilerin sayı duyusunun düşük olmasının nedenlerinden birini Yang, Reys ve Reys (2009) çalışmasında öğretmenlerin öğrencilere sayı duyusunu geliştirmede nasıl yardım edeceğini bilmemeleri ve kendilerinin sayı duyularının yetersiz hissetmeleri biçiminde ifade etmiştir. Bu bağlamda ilgili literatür (Er ve Artut, 2015; Er ve Artut, 2016; Şengül, 2013; Tsao, 2005; Yang, 2007) incelendiğinde öğretmenlerin ve öğretmen adaylarının da sayı duyularının düşük olduğu görülmüştür. 
Er, Z., Dinç Artut, P. (2017). Sekizinci sınıf öğrencilerinin doğal sayı, ondalıklı sayı, kesirler ve yüzde konularında kullandıkları sayı duyusu stratejilerin incelenmesi. International Journal of Social Sciences and Education Research, 3(1), 218-229.

Bu çalışmada dağal sayılar, ondalıklı sayılar, kesirler ve yüzdeler konularına göre öğrencilerin kullandıkları stratejiler incelendiğinde, öğrencilerin daha yüksek $(\% 36,50)$ oranda yüzdeler konusuna ilişkin problemlerde sayı duyusu temelli stratejiyi çözümlerinde kullandıkları görülmüştür. Diğer yandan bu çalışmada öğrencilerden elde edilen çözümlerde sayı duyusu temelli stratejilerinin en düşük $(\% 6,78)$ oranda kullanılan konunun kesirler olduğu sonucuna ulaşılmıştır.

Reys, Kim ve Bay, 1999; Yang (2002) tarafından yapılan çalışmada kesirler konusunda öğrencilerin sayı duyusu gelişimlerinin belirlendiği çalışmada da öğrencilerin kesirler konusunda sayı duyusu performanslarının düşük olduğu görülmüştür. Bunun yanı sıra kesirlerde ve ondalık sayılarda sayı duyusu kullanımına ilişkin Suh, Johnston, Jamieson ve Mills (2008) tarafından yapılan çalışma da benzer sonuçlar elde edilmiştir. Tsao (2005) kesir, ondalık sayı, tam sayılar ve işlemlerle ilgili sayı duyusu problemlerinden oluşan, öğretmen adayları ile yaptığı çalışmada da öğretmen adayları tarafından en çok zorlanılan bölüm kesirlerle ilgili olan sayı duyusu problemler olduğu sonucuna ulaşmıştır.

Ayrıca bu çalışma da kesirler konusuna ilişkin sayı duyu testinde yer alan yedi maddeden beş tanesi sayı duyusu bileşenlerinden sayı kavramını anlama bileşenine yönelik maddeleri içermektedir. Literatürde sayı duyusu bileşenlerine göre öğrencilerin kullandıkları stratejilerin incelendiği çalışmalarda (Yang, 2007; Tsao ,2005) , öğrencilerden elde edilen çözümlerde sayı duyusu temelli stratejilerinin en düşük oranda kullanılan bileşenin sayı kavramını anlama bileşeni olduğu sonucuna ulaşılmıştır. Dolayısıyla bu araştırmadan elde edilen araştırma bulguları ile yukarıda belirtilen araştırma bulgularının paralel olduğu söylenebilir.

Eraslan (2009) çalışmasında Finlandiya'nın PISA sınavındaki başarısın altında yatan nedenleri; öğretmen yetiştirme programı, geleneksel okul yaşamı, kültürel olarak öğretmenlik mesleğine bakış ve hizmet içi öğretmen eğitimi olmak üzere dört faklı başlık altında incelemiştir. Geleneksel okul yaşamı açısından, Finlandiya'da zorunlu temel eğitim boyunca, değerlendirme adına herhangi bir ulusal sınav veya yılsonu sınavı olmayıp, öğrenciler öğretmenin hazırladığı sorularla değerlendirilmekte olduğunu belirtmiştir. Ülkemizde öğrencilerin eğitim hayatları boyunca yorum gerektiren problemlerden ziyade çok sayıda test çözmeyi ve bir dizi kural ezberlemeyi gerektiren sınavlara tabi tutulmaları da onların kural temelli stratejiyi tercih etmelerinin bir başka nedeni olarak düşünülebilir.

Sonuç olarak bu araştırama da doğal sayılar, ondalıklı sayılar, kesirler ve yüzde konularına yönelik öğrencilerden elde edilen tüm çözümler incelendiğinde öğrencilerin çözümlerin de daha çok kural temelli stratejileri kullandıkları görülmüştür.

Sayı duyusunun önemi göz önüne alındığında, sayı duyusu kavramının, öğrencilerin matematik gelişimleri üzerindeki öneminin anlaşılması için öğretmenlere yönelik hizmet içi eğitim programları düzenlenebilir. Programda sayı duyusu ile ilgili yeterli sayıda kazanımlara ve etkinliklere yer verilerek, sayı duyusunun gelişimi sağlanabilir. Bu araştırmada doğal sayılar, ondalıklı sayılar, kesirler ve yüzde kavramına ilişkin maddeler oluşturulurken bileşenlere yönelik eşit sayıda maddeler oluşturularak konulara ilişkin daha detaylı çalışmalar yapılabilir.

\section{Kaynakça}

Altay, M. (2010).Illköğretim ikinci kademe ögrencilerin sayı duyularının; sinıf düzeylerine, cinsiyete ve sayı duyusu bileşenlerine göre incelenmesi. Yayımlanmış Doktora Tezi, Hacettepe Üniversitesi, Ankara 
Er, Z., Dinç Artut, P. (2017). Investigation of number sense strategies used by eight grade on the subject of natural numbers, decimal numbers, fractions, percentages of eight grade students. International Journal of Social Sciences and Education Research, 3(1), 218-229.

Bakanlığı, M. E. (2013). İlköğretim kurumları (ilkokullar ve ortaokullar) fen bilimleri dersi (3, 4, 5, 6, 7 ve 8. sinıflar) öğretim programı. Erişim Tarihi, 15, 2016.

Courtney-Clarke, M. A. E. (2012). Exploring the number sense of final year primary pre-service teachers (Doctoral dissertation, Stellenbosch: Stellenbosch University).

Er, Z. \& Artut, P. D. (2016). An Investigation of Elementary School Teachers' Sense of Number. US-China Education Review, 6(4), 205-217.

Er, Z. ve Artut, P. D. (2015). Identification of Number Sense Strategies Used By Elementary School Teachers and Math Teachers. The 3rd International Eurasian Educational Research Congress , 31 May-3 June 2016, Muğla Sitkı Kocaman Universty, Muğla, Turkey.

Eraslan, A. (2009). Finlandiya'nın PISA'daki Başarısının Nedenleri: Türkiye için Alınacak Dersler. Necatibey Eğitim Fakültesi Elektronik Fen ve Matematik Eğitimi Dergisi, 3(2).

Gay, S. A. ve Aichele, D. B. (1997). Middle school students' understanding of number sense related to percent. School Science and Mathematics, 97 (1), 27-36.

Greeno, J. G. (1991). Number sense as situated knowing in a conceptual domain. Journal for research in mathematics education, 170-218.

Harç, S. (2010). 6. Sınıf öğrencilerinin sayı duygusu kavramı açısından mevcut durumlarının analizi. Unpublished master's thesis, Marmara University, Istanbul.

Hope, J. (1989). Promoting number sense in school. The Arithmetic Teacher, 36(6), 12.

National Council of Teachers of Mathematics (NCTM). (2000). The principles and standards for school mathematics. Reston, VA: Author.

Reys, B. J., Kim, O. K., ve Bay, J. M. (1999). Establishing fraction benchmarks. Mathematics Teaching in the Middle School, 4 (8), 530-532.

Reys, R. E., \& Yang, D. C. (1998). Relationship between computational performance and number sense among sixth-and eighth-grade students in Taiwan. Journal for Research in Mathematics Education, 225-237.

Reys, R., Reys, B., Emanuelsson, G., Johansson, B., McIntosh, A., \& Yang, D. C. (1999). Assessing number sense of students in Australia, Sweden, Taiwan, and the United States. School Science and Mathematics, 99(2), 61-70.

Sengul, S., \& Gulbagci, H. (2012a). An investigation of 5th grade Turkish students' performance in number sense on the topic of decimal numbers. Procedia-Social and Behavioral Sciences, 46, 2289-2293.

Suh, J. M., Johnston, C., Jamieson, S., ve Mills, M. (2008). Promoting decimal number sense and representational fluency, Mathematics Teaching in the Middle School,14 (1), 44-50.

Şengül, S. (2013). Sınıf öğretmeni adaylarının kullandıkları sayı duyusu stratejilerinin belirlenmesi. Kuram ve Uygulamada Ĕgitim Bilimleri, 13(3), 1951-1974.

Şengül, S., \& Gülbağc1, H. (2012b). Evaluation of number sense on the subject of decimal numbers of the secondary stage students in Turkey. Int.Online Journal of Educational Sciences, 4(2), 296-310.

Tsao, Y. L. (2005). The number sense of pre-service elementary school teachers. College Student Journal, 39 (4), 647-679.

Tsao, Y. L. (2011). Effects of a problem-solving-based mathematics course on number sense of preservice Teachers. Journal of College Teaching \& Learning (TLC), 1(2).

Yang, D. C. (2002). Teaching and Learning Number Sense: One Successful Process-Oriented Activity With Sixth Grade Students in Taiwan. School Science and Mathematics, 102(3), 1-6.

Yang, D. C. (2007). Investigating the strategies used by pre-service teachers in Taiwan when responding to number sense questions. School Science and Mathematics, 107(7), 293-301.

Yıldırım, A., \& Şimşek, H. (2006). Sosyal bilimlerde nitel arastirma yöntemleri. Seçkin Yayıncılık. 
Er, Z., Dinç Artut, P. (2017). Sekizinci sınıf öğrencilerinin doğal sayı, ondalıklı sayı, kesirler ve yüzde konularında kullandıkları sayı duyusu stratejilerin incelenmesi. International Journal of Social Sciences and Education Research, 3(1), 218-229.

\section{Extended Abstract in English}

The concept of number sense is a significant one in mathematics education. According to the standards of NCTM (2000, p.32), it is stated that students understand the numbers, the ways of representing the numbers, the relationships between the numbers and number systems, the meanings of operations, the relationships of the numbers with each other and they can do fluent computations and appropriate predictions and it is emphasized that the concept of number sense should have been developed based on these standards.

There are various definitions about the concept of number sense in the literature. Greeno (1991) defined the number sense as flexible thinking, the skill of prediction in computation and the skill of discernment about the quantity. McIntosh, Reys and Reys (1992) describe number sense as: "a person's general understanding of number and operations along with the ability and inclination to use this understanding in flexible ways to make mathematical judgments and to develop useful strategies for handling numbers and operations" (cited Morais and Serrazina, 2013).

In this research, the aim is to determine the strategies which the $8^{\text {th }}$ grade students use in number sense problems involving on the subject of natural numbers, decimal numbers, fractions, percentages. In this research, a descriptive study was designed as a cross hatching model. There were two techniques used for data collection; which were quantitative and qualitative methods. The quantitative participants of the research consisted of 200 students who were attending at the $8^{\text {th }}$ grade of three middle schools in Adana. The qualitative participants of the research consisted of 40 students who attending 3 different middle schools and identifying according to voluntary basis.

As the data collection tool, a number sense test (NST) which consisted of some questions in the number sense scale of Singh (2009), which was originally adapted from McIntosh, Reys, Reys Bana, and Farrell, (1997) was used. The data obtained through the data collection tool were analyzed via quantitative and qualitative analysis technics.

The data were obtained through NST and interview technique. As data, 200 answer sheets of the $8^{\text {th }}$ grade students to number sense test were used. The interviews were made with the 40 students in order to specify how they thought while solving questions in the number sense test.

NST was administered to each student individually. Throughout the implementation, the students were told that they were expected to solve the questions in the number sense test in the way that came to their mind first. After the students finished answering the items in the test, they were interviewed to designate the strategies they used while solving the questions. During the interviews, the students' answers to the questions in the test were shown to them again, they were asked to tell how they reached that solution and to tell how they thought while solving the questions. The interviews were recorded by a voice recorder.

The students' answers to the questions in the test and their ways of solution were analyzed through qualitative analysis methods. First, the correct answers to each question in the test were evaluated and coded as 1 and incorrect answers were evaluated and coded as 0 . Next, qualitative analysis was carried out on the data which was transferred from voice recordings into a written form. The students who were interviewed were coded as S1, S2, .. in order not to make their identities public. After the findings in the related literature were studied, the strategies which were 
Er, Z., Dinç Artut, P. (2017). Investigation of number sense strategies used by eight grade on the subject of natural numbers, decimal numbers, fractions, percentages of eight grade students. International Journal of Social Sciences and Education Research, 3(1), 218-229.

used in the solution of number sense problems were coded under four categories strategy based on number sense (SBNS), strategy partially based on number sense (SPBNS), strategy based on rules (SBR) and the answers that have no explanation (no explanation).

According to the findings obtained from the analysis of quantitative and qualitative data, it was seen that the students had low number sense performances and that the solutions of the students also used more rule based strategies. In line with this, it can be recommended that more studies which support the usage of the strategies of number sense can be presented during their education. 